\title{
Biron - Le Château
}

\section{Guillaume Demeure}

\section{OpenEdition \\ Journals}

Édition électronique

URL : http://journals.openedition.org/adlfi/7772

ISSN : 2114-0502

Éditeur

Ministère de la culture

Référence électronique

Guillaume Demeure, "Biron - Le Château », ADLFI. Archéologie de la France - Informations [En ligne], Aquitaine, mis en ligne le 01 mars 2007, consulté le 02 mai 2019. URL : http://

journals.openedition.org/adlfi/7772

Ce document a été généré automatiquement le 2 mai 2019.

(c) Ministère de la Culture et de la Communication, CNRS 


\title{
Biron - Le Château
}

\author{
Guillaume Demeure
}

Identifiant de l'opération archéologique : 025298

Date de l'opération : 2007 (SU)

1 Le château de Biron installé aux confins du Périgord et de l'Agenais, est le siège de l'une des quatre baronnies du Périgord. Situé sur une hauteur (altitude 233m), le château est le résultat de la juxtaposition des constructions entreprises par les seigneurs successifs. Les modifications, les reprises et les ajouts sont très nombreux et parfois complexes. La fouille a fait suite à la mise au jour de vestiges maçonnés dans le cadre d'une vaste campagne de travaux de restauration et de mise en valeur du site entreprise depuis plusieurs années par le conseil général de la Dordogne propriétaire du site.

2 Sur une superficie d'environ $45 \mathrm{~m}^{2}$, la fouille et une analyse rapide du bâti environnant ont permis la mise en évidence de trois grandes phases chronologiques.

3 Le premier état de ce secteur du château se dessine autour du XIII ${ }^{e} \mathrm{~s}$. avec une tour maîtresse, d'au moins trois étages, conservée sur la majeure partie de son élévation, de plan carré, sans contrefort, flanquée à l'est d'un bâtiment à deux niveaux minimum, mis au jour par la fouille. Depuis la basse-cour, un accès perché avec barre intramurale permet la distribution soit vers la tour par un escalier rampant en pierre, ce qui constitue une rareté pour la période, soit vers l'intérieur du bâtiment. La fonction de ce bâtiment reste incertaine, mais il pourrait s'agir d'un logis primitif, partie prenante de l'enceinte. La destination de chacun des étages de la tour ne peut, en l'état des recherches, qu'être le fruit de suppositions. Le niveau 1 peut être un espace de stockage et le niveau 3 sous voûte où accède l'escalier, plus richement équipé, peut être destiné à la résidence même si la superficie intérieure relativement faible limite cette éventualité. Le faciès de cette tour s'apparente en effet aux tours-beffrois que l'on rencontre fréquemment en Périgord, Quercy et Limousin. 
4 Suite aux sièges de la guerre de Cent Ans, l'ensemble du site est profondément remanié et les vestiges du logis disparaissent sous une terrasse correspondant à une adaptation de la défense aux progrès de l'artillerie. Tout l'agencement intérieur de la tour est revu. Le mobilier archéologique retrouvé dans les niveaux de remblais situe cette phase vers la fin $\mathrm{du} \mathrm{XV}^{\mathrm{e}} \mathrm{s}$.

5 Enfin, les importants travaux initiés au début du XVII ${ }^{\mathrm{e}}$ s. mais finalisés seulement un siècle plus tard donnent lieu à l'agrandissement de la terrasse pour en faire un espace d'agrément et à l'ouverture d'un portail dans le mur reliant la tour de la recette à la zone étudiée.

6 Cette opération restreinte laisse de larges zones d'ombres mais a cependant le mérite d'ouvrir une première fenêtre archéologique sur un site peu étudié.

7 Il faut également souligner que ces importantes élévations enterrées augurent un puissant potentiel archéologique pour les terrasses modernes plus au nord, il en effet fréquent que les sites castraux qui perdurent au-delà du Moyen Âge connaissent de grande phase de remblaiement en période des Temps Modernes noyant mais également préservant une grande partie des structures médiévales.

8 (Fig. $n^{\circ} 1$ : Vue principale du secteur d'intervention)

9 DEMEURE Guillaume

\section{ANNEXES}


Fig. $n^{\circ} 1$ : Vue principale du secteur d'intervention

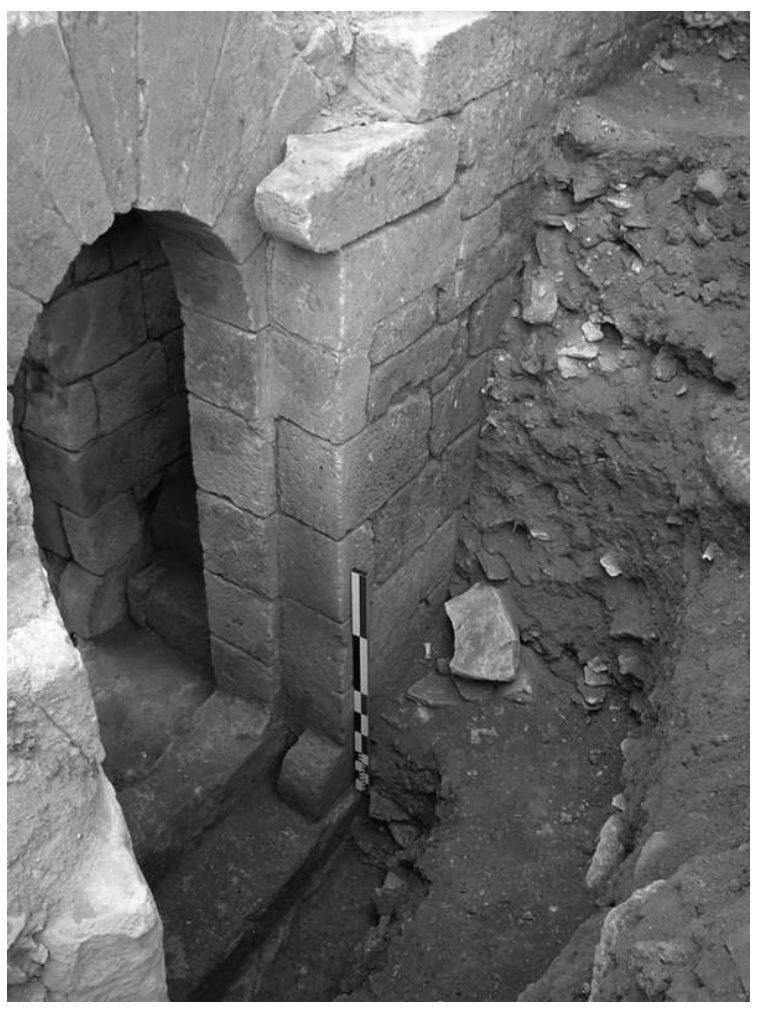

(2007)

INDEX

operation Sauvetage urgent (SU)

Index géographique : Aquitaine, Dordogne (24), Biron

Thèmes : artillerie, basse-cour, beffroi, château, chronologie, conservation-restauration, défense, édifice, escalier, étage, guerre, mobilier, porte, remblai, site de hauteur, stockage, terrasse, tour

Index chronologique : Moyen Âge, Temps Modernes

\section{AUTEURS}

\section{GUILLAUME DEMEURE}

EP 